\title{
ENHANCED FIELD OBSERVATION BASED PHYSICAL AND NUMERICAL MODELLING OF TSUNAMI INDUCED BOULDER TRANSPORT PHASE 1: PHYSICAL EXPERIMENTS
}

\author{
Jan Oetjen ${ }^{1}$, Max Engel ${ }^{2}$, Helmut Brückner ${ }^{2}$, Shiva P. Pudasaini ${ }^{3}$, Holger Schüttrumpf ${ }^{1}$
}

\begin{abstract}
Coasts around the world are affected by high-energy wave events like storm surges or tsunamis. By focusing on tsunami impacts, we investigate tsunami-induced transport of boulders by an interdisciplinary combination of field observations, laboratory experiments and advanced numerical modelling. In phase 1 of the project we conduct physical laboratory experiments based on real-world data. Following the experimental phase we will develop an enhanced numerical boulder transport model (BTM) based on an existing two-phase model.
\end{abstract}

Keywords: tsunami; boulder transport; physical experiments; numerical modelling

\section{Introduction}

Coasts are crucial areas for living, economy, transportation, and all sectors of industry. Many of them are periodically affected by high-energy wave events. Referring to Neumann et al. (2015) and depending on the applied scenario for population growth, in 2060 between 1,052 and 1,388 million people will live within the low-elevation coastal zones. Compared to the 625 million inhabitants today, this is equivalent with an increase between $68 \%$ and $122 \%$. Therefore, there is an urgent need to improve the understanding of the characteristics, maximum magnitudes, recurrence intervals and socioeconomic impacts of high-energy wave events (Huntington et al., 2007; Knutson et al., 2010; Vose et al., 2014). Marine-borne geological deposits in coastal geo-archives provide essential information on long term, prehistoric frequency-magnitude patterns of high-energy wave events. This is a basic requirement for long-term coastal hazard management (Engel et al., 2014). Fine-grained deposits may quickly be altered after such events and may not be preserved in the sedimentary record (Engel \& Brückner, 2011). Coarse clasts with weights of more than $80 \mathrm{t}$ (so called boulders, a-axis $>0.25 \mathrm{~m}$ or blocks, a-axis $>4.1 \mathrm{~m}$ ), which were dislocated by extreme waves, represent more reliable records in terms of preservation potential and should Therefore be used for the investigation of past events. For establishing an accurate chronology and typing of high-energy wave events and classifying them in terms of risk assessments, it is necessary to detect whether the boulders were moved by storm or tsunami.

However, differentiating between storm- and tsunami-dislocated clasts is a challenge, and therefore the development of reliable approaches and tools to solve this issue, preferably based on field observations, is essential to accurately assess extreme coastal hazards. Such tools can be numerically coupled tsunami and boulder transport models (BTM) supporting the in situ work of geologists, geographers, engineers and other researchers. To analyze boulder deposits numerically, two basic approaches are applied nowadays: (i) inverse modelling uses specific boulder characteristics as input for analytic equations. These equations (e.g. Nott, 1997; Pignatelli et al., 2009; Nandasena et al., 2011a; Benner et al., 2010; Engel \& May, 2012) describe the necessary threshold wave height or wave velocity to displace a boulder of known dimensions and density by the use of momentum balances. Those equations only provide rough estimates for minimum wave energy since they do not consider the complex non-linear interactions between turbulent flow fields and boulders. (ii) On the other hand, forward models (e.g. Imamura et al., 2008; Zainali \& Weiss, 2015) operate numerically and calculate tsunami-induced boulder movements from given wave characteristics in more detail. Their validation and calibration on the basis of physical measurements or observations is essential. This can be achieved by field observations (e.g. Nandasena et al., 2011b) and physical experiments (e.g. Imamura et al., 2008). However, current forward models still suffer from insufficient quantitative understanding of essential processes during boulder transport by waves. So far, only very few major tsunami events allows the field-observation based validation of numerical models (e.g. Indian Ocean Tsunami 2004;

\footnotetext{
${ }^{1}$ Institute for Hydraulic Engineering and Water Resources Management, RWTH Aachen University, Germany

${ }^{2}$ Institute of Geography, University of Cologne, Germany

${ }^{3}$ Faculty of Mathematical and Natural Sciences, Steinmann Institute, Department of Geophysics, University of Bonn, Germany
} 
Goto et al., 2010; Nandasena et al., 2011b). Thus, well controlled laboratory experiments are essential for systematic calibration processes of numerical hydrodynamic models.

\section{Boulder transport modelling}

Wave-induced transport of any three-dimensional solid body is influenced by many dynamic variables and parameters, which can be classified in three groups:

1. Hydrodynamic forces: Transport-inducing and wave-induced forces accounting for the impact forces on the body,

2. Body characteristics: Body-inherent characteristics like shape, density or dimensions, etc.

3. Environment: Topography, surface roughness, bathymetry and boulder pre-transport setting, etc.

None of these variables and parameters is simple to determine in the field or easy to reproduce in the laboratory or numerically, and many uncertainties remain.

\section{Hydrodynamic forces}

Existing inverse models commonly consider drag, inertia, lift, friction and (reduced) gravity as impact or restraining forces (Sugawara et al., 2014 and references therein). Figure 1 displays these basic hydrodynamic forces acting on an idealized boulder during wave impact. The lift and reduced gravity forces are also influenced by the initial boulder location, which will be discussed later in more detail. By considering particular boulders in the field, in most cases no accurate observations or even measurements of the transport-inducing event are available. In most cases, the event itself is not known (e.g. Hisamatsu et al., 2014; Prizomwala, 2015). Therefore, none of the hydrodynamic variables such as wave length, wave height or amplitude is known; they need to be estimated from today's obtainable indicators, like boulder characteristics. However, with the existing numerical models (forward and inverse) it is not possible to determine the necessary wave length, velocity and height with required and high accuracy which is necessary for distinguishing between storm and tsunami (e.g. Zainali \& Weiss, 2015). Shortcomings include the treatment of the boulder as an isolated, single and idealized body or the utilization of rough estimated regionally uniform coefficients (e.g. for drag coefficient) in available numerical models (Sugawara et al., 2014; Hisamatsu et al., 2014). Therefore, since wave length and velocity are crucial parameters for the distinction between storm and tsunami waves, advancements in numerical modelling are essential.

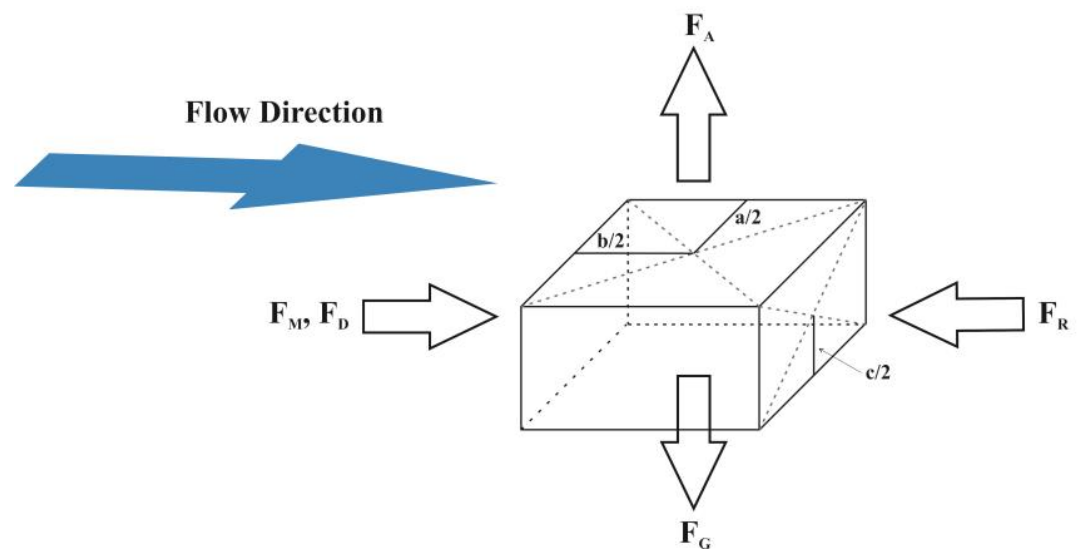

Figure 1. Basic impact forces related to hydrodynamics. FM: Inertia; FD: Drag; FA: Lift; FG: Gravity; FR: Friction (Pignatelli et al., 2009).

\section{Body characteristics}

The body characteristics are unique for every single boulder deposit. All known numerical and laboratory BTM use idealized boulder shapes and homogeneous densities for simulations (e.g. Imamura et al., 2008; Nandasena \& Tanaka, 2013; Liu et al., 2014). However, a simplified shape, such as a rectangular prism or cube, might be more or less exposed to friction and drag forces than the natural irregular counterpart. Combined with uncertainties associated with assumptions of bottom friction, idealized boulder shapes lead to largely inaccurate results for the predominant transport mode, e.g. rolling, sliding, saltation (Etienne et al., 2011) or a combination of these (Figure 2a). Furthermore, the 
impact of hydrodynamic forces on a complex shape will differ substantially from the impact on rectangular shapes. Not to mention micro-turbulences on irregular boulder surfaces, the impact will noticeably decrease the more the boulder front converges towards a shape with little drag. Zainali Weiss (2015) recently pointed out the importance of the boulder aspect ratio of rectangular bodies for transport in a fluid. Investigating the behavior of more complex bodies and the comparison to idealized bodies will Therefore lead to new insights of how the shape influences boulder transport mechanisms.

\section{Environment}

Bathymetry and topography strongly influence the flow and wave characteristics. They determine the distance between the wave breaking point and the initial boulder location. After the wave breaks, the flow front becomes supercritical with increasing Froude number because the flow becomes shallower and faster (e.g. Zainali \& Weiss, 2015). This problem can be adequately treated numerically with high-resolution adaptive computational grids (in time and space). Then, the results can be validated with accurate field measurements. Furthermore, the onshore transport distance of a boulder will be significantly influenced by the pretransport setting: whether the boulder is initially subaerial, submerged, partially submerged and/or joint-bounded (Figure 2b) (Zainali \& Weiss, 2015). During the initial wave impact and depending on the submergence of a boulder, particular forces can be neglected or additional forces need to be considered. A subaerial boulder will initially be affected by full gravity, while reduced gravity needs to be considered if flow depth exceeds boulder height. In addition, a boulder connected with the cliff first needs to be detached and temporarily enhanced restraining forces have to be applied (e.g. Noormets et al., 2004). The transport mode of the boulder is highly affected by macro- and micro-topography (bottom roughness). A complex shaped boulder with sharp edges, e.g. in karstified reef rock, on a very rough ground tends to rolling or even saltation, whereas the same boulder on a plain ground will preferably move by sliding. An accurate numerical boulder transport model needs to account for all possible initial boulder locations, pre-transport settings, bottom roughness and dominant forces.

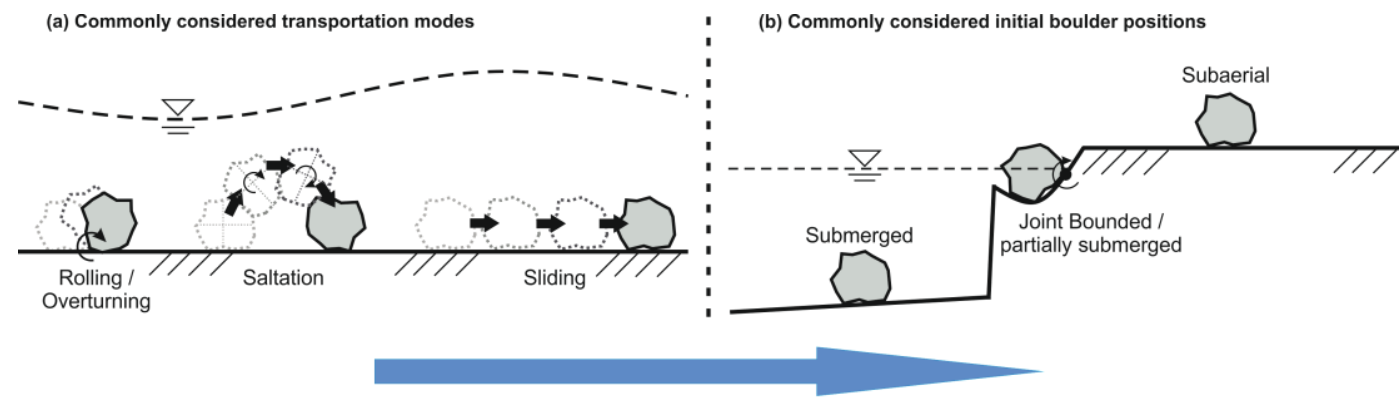

Flow Direction

Figure 2. Boulder transportation modes (a) and initial positions relative to water level (b) which are commonly considered in numerical models.

\section{Physical boulder transport modelling}

A fundamental requirement of a numerical model is its ability to reproduce nature as accurately as possible. For verification purposes, several highly developed laboratory experiments on tsunami generation, propagation and inundation have been established in which researchers follow divergent approaches regarding tsunami characteristics and wave generation (e.g. Penchev, 2008). However, realistic laboratory experiments focusing on boulder transport mechanism due to tsunami waves are still rare (Martinez et al., 2011; Nandasena \& Tanaka, 2013; Liu et al., 2014; Bressan et al., 2015); even some of the most basic processes, e.g. influence of boulder shape and sedimentary load on hydrodynamics, are not or not entirely understood. Imamura et al. (2008) conducted laboratory experiments in an open channel ending on a slope, and compared the results with those of their numerical BTM. This model setup - a plain bed ending on a slope - is to our knowledge the only today conducted setup type for experimental boulder transport modelling (e.g. Nandasena \& Tanaka, 2013; Bressan et al., 2015). Except for Sangster et al. (unpublished) and Martinez et al. (2011), who used near to spherical bodies and marbles, respectively, all experiments involve only rectangular boulder replicas. These results in significantly different transport behavior as compared to realistic shapes due to, for instance, variations of the drag force. Modelling the broken tsunami 
wave as a bore is widely accepted (Sugawara et al., 2008). To our knowledge, the only laboratory boulder transport experiments in which the velocity and orientation of boulders are measured directly directly out of the (idealized) boulder are conducted by Agnieszka Strusińska-Correia at the Leichtweiß-Institute for Hydraulic Engineering and Water Resources at the Technical University of Braunschweig. However, so far no results have been published in this context. Summarized, no laboratory experiments are known which consider for complex boulder bodies, non-uniformly sloped bathymetries and sedimentary load in a tsunami bore.

\section{Case study "Island of Bonaire"}

The foundation of the presented research project lies in a case study at the Island of Bonaire (southern Caribbean, Leeward Antilles, Figure 3). Large limestone boulders were transported from the cliff edge of the island landward during high-energy wave events in the past. However, the transport causing event (paleo-tsunamis or severe hurricanes) is still discussed highly controversial (e.g. Scheffers 2005; Spiske et al., 2008; Watt et al., 2010; Engel \& May, 2012).

We applied an iterative approach simulating historical and other potential tsunami events in the Caribbean Sea in order to identify the most suitable event(s) for creating sediment patterns on Bonaire as well as the source of possible future threats (Oetjen et al., 2015).

Delft 3D (Deltares, 2014a) and DelftDashboard (Deltares, 2014b) of Deltares systems (NL) was utilized to compute different tsunami scenarios for Bonaire (Table 1, Figure 3). The initial, tsunami triggering, earthquake was simulated using DelftDashboard (DD). As result DD generated an initial input file used for Delft 3D in which the tsunami propagation across the Caribbean Sea and the impact at Bonaire's coastline are computed in depth-averaged 2D.

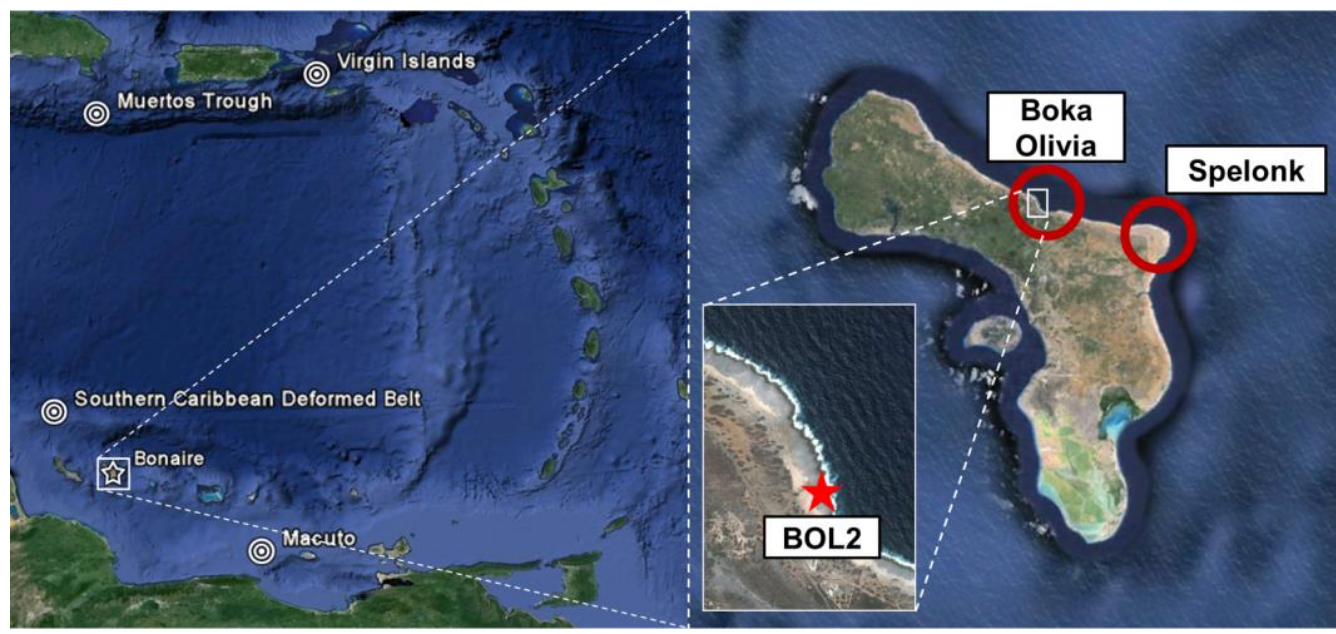

Figure 3. Location of Bonaire and the earthquale scenarios (left). Location of the study areas on Bonaire and the largest boulder BOL2 at Boka Olivia (right).

Table 1. Parameters of the simulated tsunami scenarios.

\begin{tabular}{|c|c|c|c|c|c|}
\hline & & Macuto & $\begin{array}{l}\text { Virgin } \\
\text { Islands }\end{array}$ & $\begin{array}{l}\text { Muertos } \\
\text { Trough }\end{array}$ & $\begin{array}{c}\text { Southern } \\
\text { Carib.Deformed } \\
\text { Belt }\end{array}$ \\
\hline & & Wit. & Wit. & Hyp. & Hyp. \\
\hline \multirow{4}{*}{ 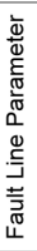 } & Year & 1900 & 1867 & {$[-]$} & {$[-]$} \\
\hline & Magnitude $[\mathrm{Mw}]$ & 7.79 & 7 & 8.79 & 8.34 \\
\hline & Length [km] & 144 & 49 & 554 & 302 \\
\hline & Width [km] & 100 & 39 & 130 & 100 \\
\hline & Ref. & $\begin{array}{l}\text { Lander et } \\
\text { al. (2002) }\end{array}$ & $\begin{array}{l}\text { Barkan \& ten } \\
\text { Brink }(2010)\end{array}$ & $\begin{array}{l}\text { Bruña et al. } \\
(2014)\end{array}$ & IOC (2012) \\
\hline
\end{tabular}


We applied a multi-scale modelling approach of three scales where we utilized two coarse models based on the GEBCO08 bathymetry data set (GEBCO, 2014) and one of higher resolution around Bonaire applying data provided by Gonzalez-Lopez \& Westerink (University of Notre Dame) with a spatial resolution of $500-600 \mathrm{~m}$ (Figure 4). The topography was generated with SRTM4.1 (Jarvis et al., 2008) for all models.

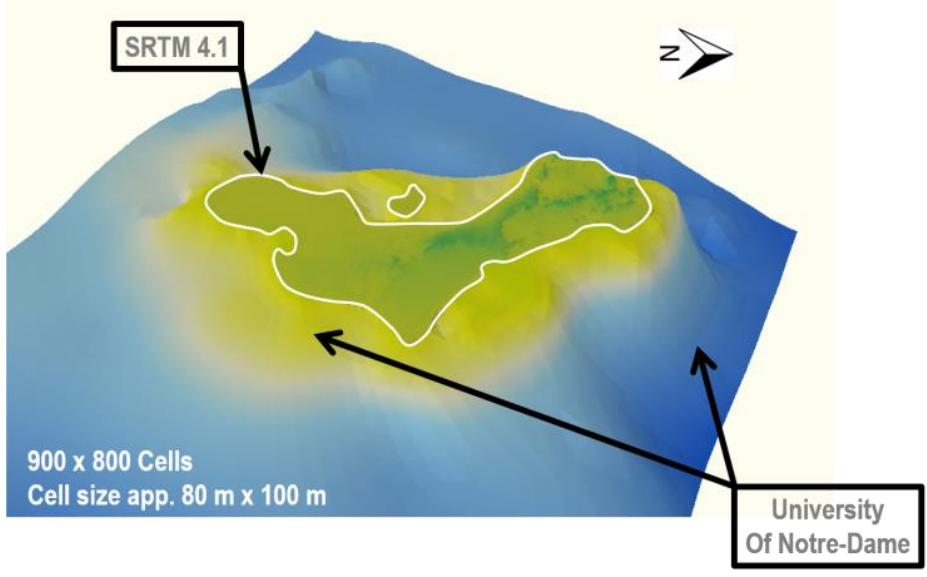

Figure 4. Model bathymetry near to Bonaires shoreline.

None of the simulated scenarios indicated a significant impact at Bonaire's shoreline. The highest waves were obtained for the Muertos Trough Scenario at Boka Olivia with a wave height of $3.4 \mathrm{~m}$ (Figure 5). According to analytical solutions for boulder transport and results of Engel \& May (2012), such a tsunami does not carry enough hydrodynamic energy to move a boulder like Bonaire's largest of app. $80 \mathrm{~m}^{3}$. Finally the results of our numerical model could not clarify whether the boulders were transported by storm waves or tsunamis and hence the corresponding discussion is still alive.

Recognizing these results and considering the scientific state of the art, we founded a research group aiming at improving the understanding of tsunami induced boulder transport and associated nearshore tsunami hydrodynamics. Therefore we conduct well controlled downscaled physical experiments utilizing field data from the Island of Bonaire. Beside the new insights gained from the physical experiments, these data are furthermore used for the validation of a new developed numerical BTM.

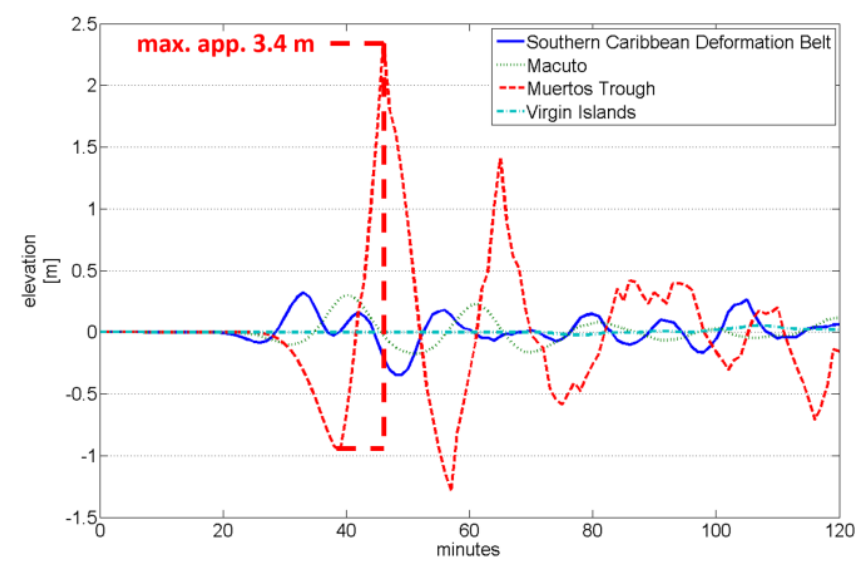

Figure 5. Computed wave heights at Boka Olivia.

\section{Physical experiments}

Within the physical experiments we want to achieve a better knowledge in terms of the hydrodynamics of nearshore tsunami behavior. Therefore we investigate three key questions:

1. Influence of realistic / non-uniform boulder shapes, 
2. Influence of (non-uniform) bathymetry/onshore topographies,

3. Influence of boulder interactions during transport,

on boulder transport path, mode, distance and deposition pattern.

The experiments are conducted in the tilting flume at Institute of Hydraulic Engineering and Water Resources Management (IWW, RWTH Aachen University Germany). The $33.5 \mathrm{~m}$ x $1 \mathrm{~m}$ x $1 \mathrm{~m}$ large flume consists of two centrifugal pumps of $30 \mathrm{~kW}$ with $400 \mathrm{l} / \mathrm{s}$ conveying capacity. In combination with the following valves and an automatical control program reproducible experiments are guaranteed (Figure 6). Bonaire's largest boulder measures $8.7 \mathrm{~m}$ x $4.8 \mathrm{~m}$ x $3.8 \mathrm{~m}$. Since the experiments scale is 1:50 the model counterpart of the boulder is approximately $18 \mathrm{~cm} \times 10 \mathrm{~cm} \mathrm{x} 8 \mathrm{~cm}$. Figure 7 shows the general setup of the physical experiments.
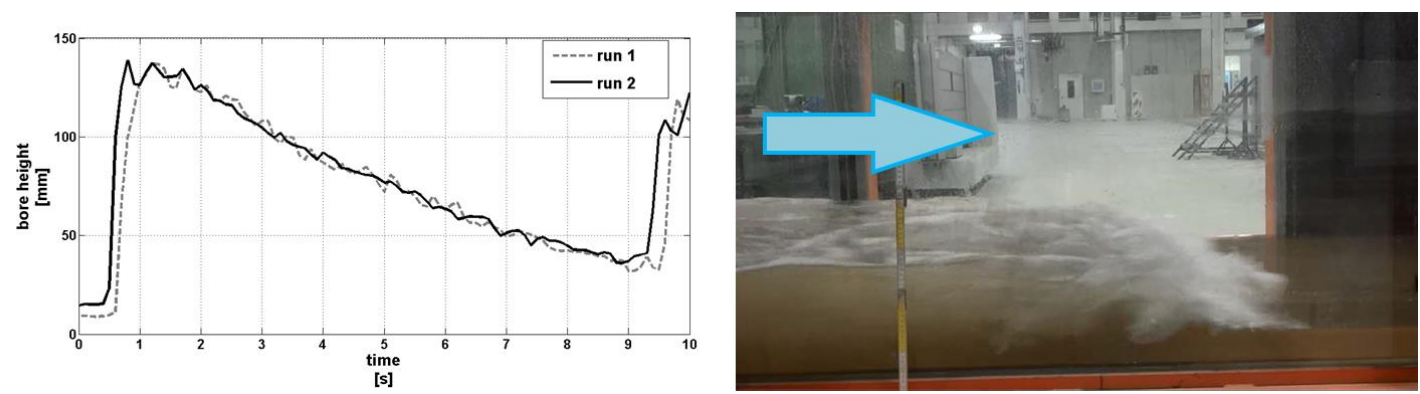

Figure 6. Left: Comparison of two test runs for bore generation in the IWW test flume. Right: Photo of a generated tsunami bore (Peltzer, 2015).

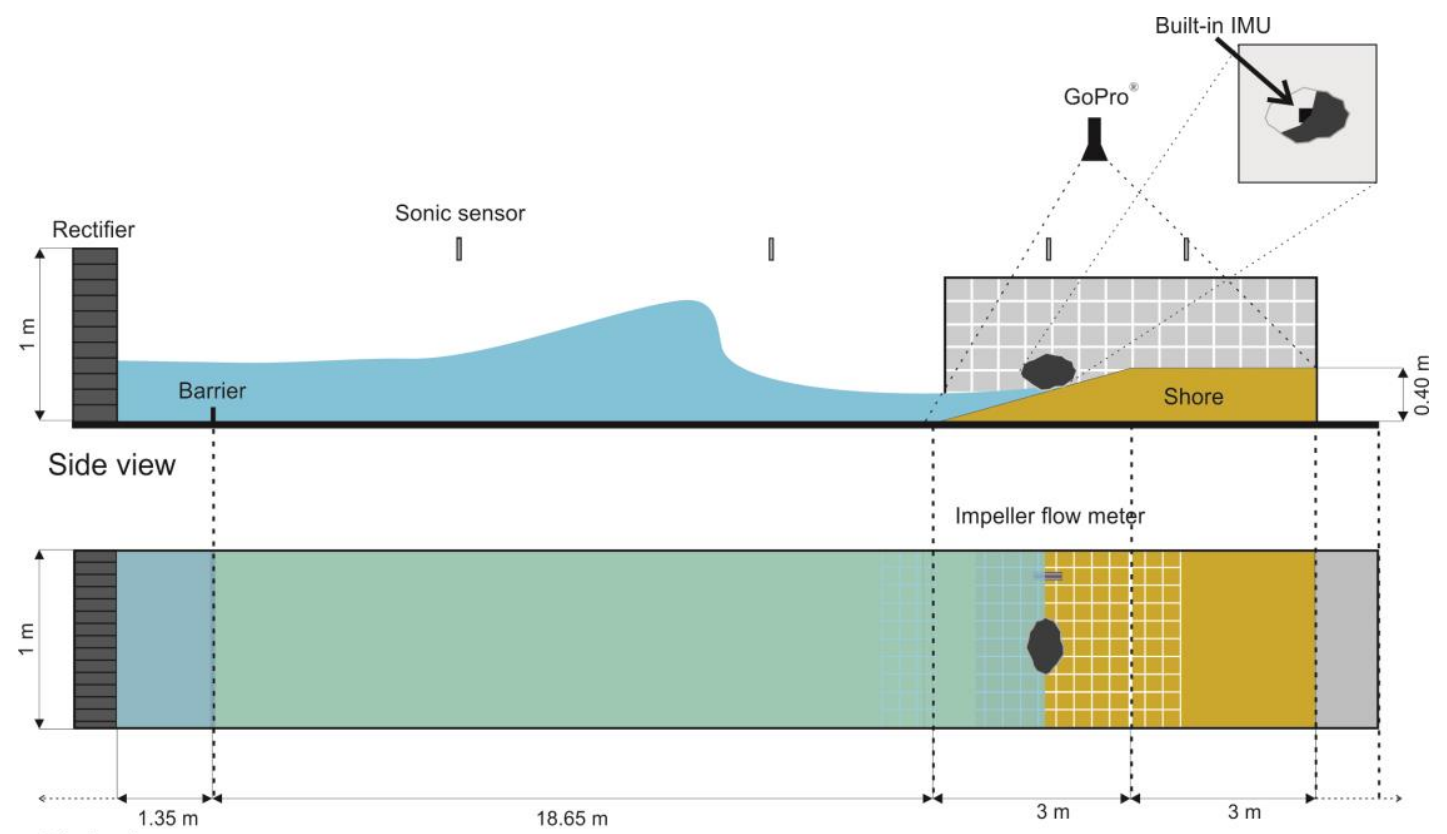

Plain view

Figure 7. Principal test setup of the flume (not to scale).

The measurement setup regarding the wave encompasses five ultrasonic sensors, one impeller flow meter as well as an acoustic doppler velocimeter (ADV). For the measurement of the boulder behavior we use inertial measurement units (IMU) and image respective video processing with Matlab ${ }^{\circledR}$.

The IMU is used for the measurement of acceleration and inclination of the boulder during the wave impact. In combination with a drawn $10 \mathrm{~cm}$ x $10 \mathrm{~cm}$ grid on the shore replica the video processing shows distance and path of the boulder during the impact. 
For the investigation of the influence of shape, boulders at the Island of Bonaire are recorded using photogrammetry. Therefore the digital photos (recorded with a Sony Cyber-shot DSC-HX200V) are computational processed (Figure 8). The obtained digital mesh can be processed further which is necessary for not reachable boulder ranges as the on ground lying part, for example. The final dataset is printed in three dimensions with a German RepRap X400 PRO ${ }^{\circledR}$ 3D printer (Figure 9). The obtained model from PETG plastic is further used as a template for a negative mask. This mask is created from silicone rubber (ELASTOSIL ${ }^{\circledR} \mathrm{M}$, Wacker Chemie AG). This two-part silicone rubber is highly suitable as the final template for the creation of the concrete boulder model. The initial fluent rubber fills the gaps of the highly irregular boulder model.

a)

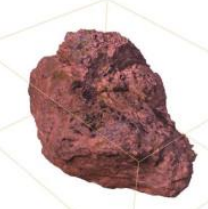

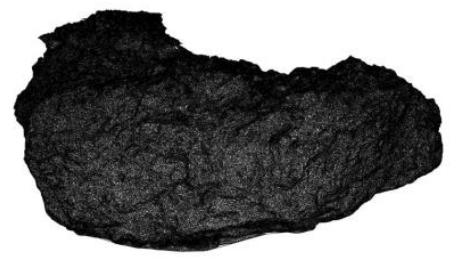
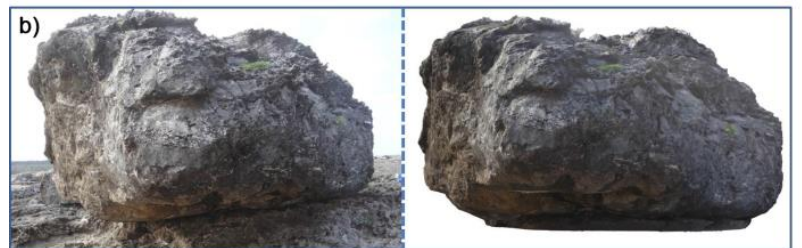

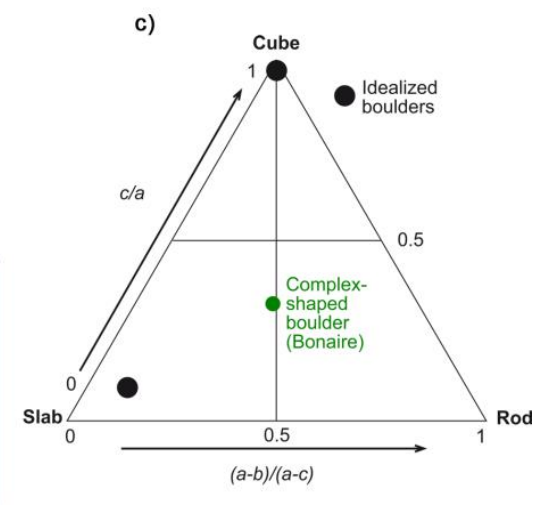

Figure 8. a) Perspective view and mesh model of a boulder deposited on Bonaire. b) Comparison between the original photograph and the numerical model). c) Contrasting shapes of idealized and complex-shaped boulders (a, b, c = main axes of boulders).

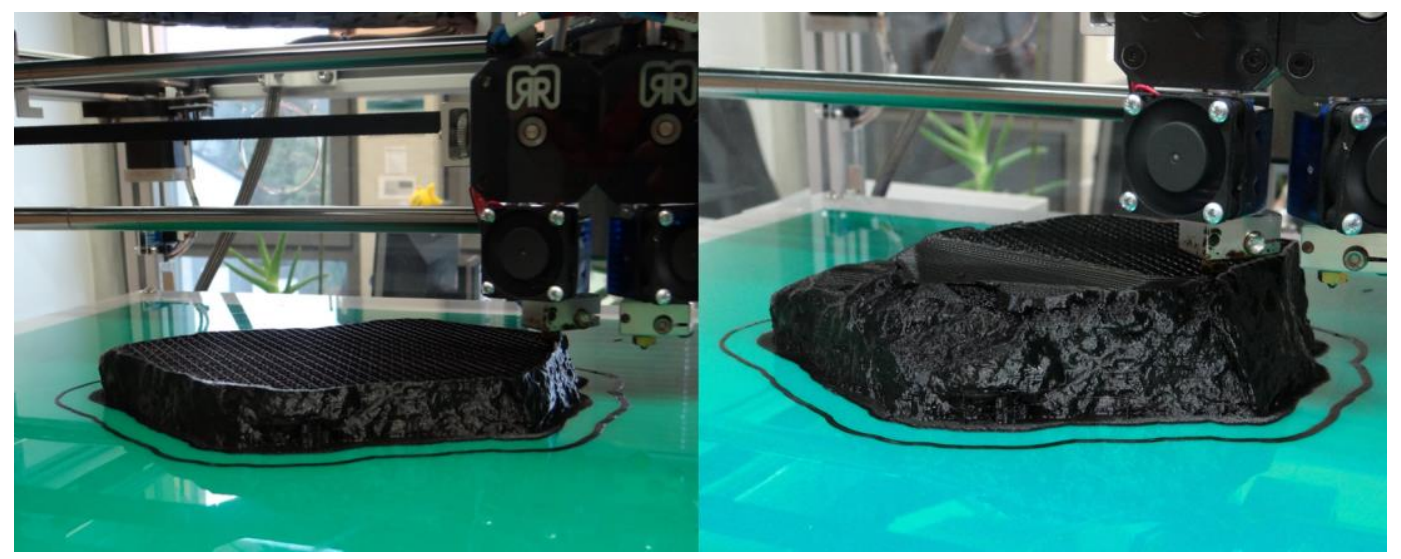

Figure 9. Printing process of the bottom part of a boulder replica in 1:50.

The IMU is finally installed inside of the boulder. We apply the Sensor Fish sensor by the Pacific Northwest National Laboratory of the U.S. Department of Energy (Figure 10, Deng et al., 2014). The Sensor Fish Gen 2 is able to store data for acceleration, rotation velocity and orientation with a sampling rate of $2048 \mathrm{~Hz}$ on a flash memory inside of the device. Therefore, the boulder model needs the possibility to remove the Sensor fish and download the data. This is realized due to a closeable thread until the boulders centroid where the sensor is inducted.

Once the non-idealized boulder models are created it is possible to compare the behavior of idealized (cubes, cuboids) to non-idealized boulder shapes in terms of transport path, distance and mode (Figure 8).

Beside the investigation of several boulder shapes we analyze the influence of the shore. Hence we constructed four divergent shore replicas (Figure 11). We use idealized replicas of Bonaire's shoreline resembling a low plunging cliff with an elevated platform, emulating the setting the model coastal boulder field on Bonaire (Engel \& May, 2012). The shores are created to change the setup comparable fast. All shores ends up at the same cuboid. The shores themselves consist of two parts that can be easily installed by one or two persons. 


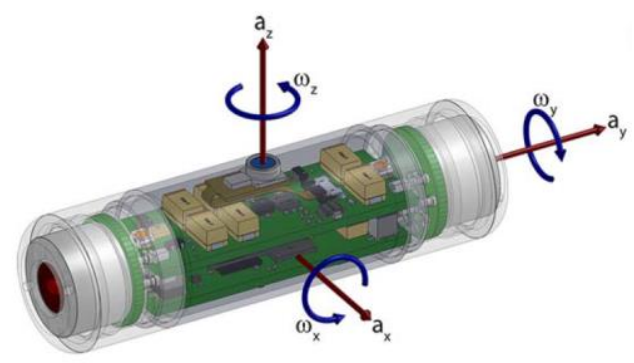

Figure 10. CAD model of the Sensor Fish Gen 2 device (Deng et al., 2014).

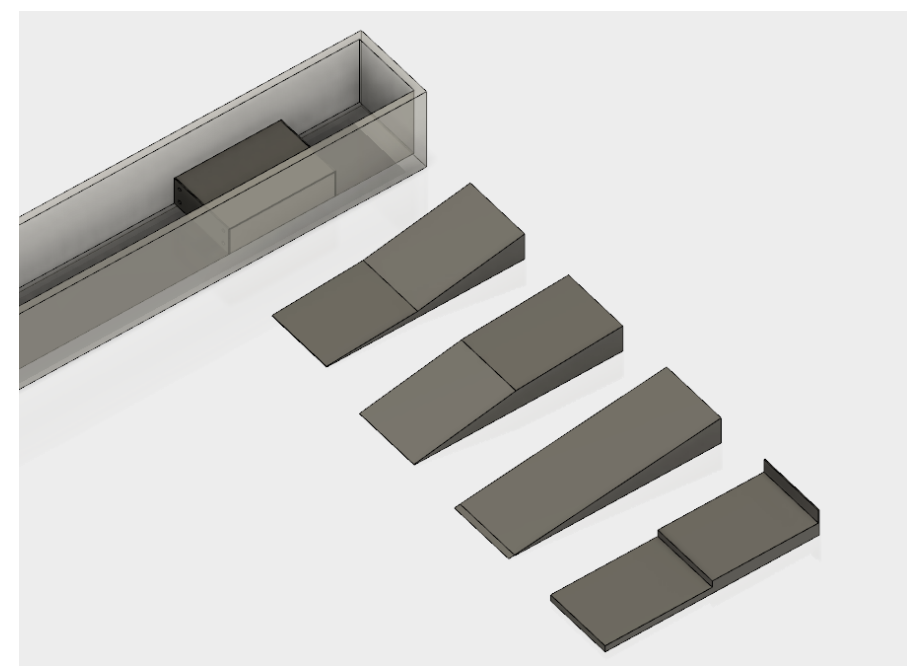

Figure 11. Shore replicas used for the physical experiments.

The experimental plan encompasses several settings regarding the initial boulder position on the shore and the submergence (full, partial, subaerial). Furthermore, we apply different wave heights.

Finally, utilizing the IMU, video processing and common measurement devices allows us to derive exactly the necessary tsunami energy to shift a boulder in motion.

\section{Phase 2: Numerical model}

Parallel to the physical experiments a numerical boulder transport model (BTM) is in development. The BTM is based on the real two-phase model of Pudasaini (2012). The model of Pudasaini solves the equations for two-phase flows (fluid and particles) explicit on a eulerian grid. In order to include the movement of a rigid boulder with an arbitrary shape the boulder is treated as an immersed boundary with the direct forcing technique (e.g. Gornak, 2013). In this context the physical behavior of the boulder within the flow will be solved with the pe Rigid Multi-Body Physics Engine of the FriedrichAlexander-University Erlangen-Nuremberg (Iglberger \& Rüde, 2009).

Hence, the development of the numerical model encompasses two essential steps:

1.Determine the crucial physical forces on the boulder,

2.Well coupling of the pe (FORTRAN 95) and the two-phase model $(\mathrm{C}++)$.

The model will be validated using the data from the physical experiments. Especially the data captured from the IMU is very helpful to determine the accuracy of the BTM highly correct.

\section{Summary}

Regarding to our experience due to the field study on the Island of Bonaire we recognized several problems in the field of numerical and physical boulder transport modelling. By conducting well controlled physical experiments utilizing real-world data we want to tackle three crucial gaps (boulder and shore shape, boulder interactions) in research. Within our project, we combine the expertise of different research fields like geographers, engineers and (geo-) physicist. By applying real world data 
for the boulder and shore models we make a step away from over-simplified model assumptions both for physical experiments and numerical modelling.

\section{REFERENCES}

Barkan, R., ten Brink, U. (2010), Bulletin of the Seismological Society of America 100 (3), 995-1009.

Benner, R., Browne, T., Brückner, H., Kelletat, D., Scheffers, A. (2010), Boulder transport by waves: Progress in physical modelling. Zeitschrift für Geomorphologie 54, Suppl. 3, 127-146.

Bressan, L., Antonini, A., Gaeta, M.G., Guerrero, M., Miani, M., Petruzzeli, V., Samaras, A. (2015), Boulder transport by tsunamis: A laboratory experiment on incipient motion. Geophysical Research Abstracts 17, EGU2015-935.

Granja Bruña, J.I., Carbó-Grosabel, A., Llanes Estrada, P., Muñoz-Martin, A., ten Brink, U.S., Gómez Ballesteros, M., Druet, M., Pazos, A. (2014), Morphostructure at the junction between the Beata ridge and the Greater Antilles island arc (offshore Hispaniola southern slope). Tectonophysics 618, 138-163.

Deltares (2014a), Delft3D-FLOW: Simulation of multi-dimensional hydrodynamic flows and transport phenomena, including sediments. Deltares, Netherlands.

Deltares (2014b), DelftDashboard. https://publicwiki.deltares.nl/display/OET/DelftDashboard.

Deng, Z.D., Lu, J., Myjak, M.J., Martinez, J.J., Tian, C., Morris, D.J., Carlson, T.J., Zhou, D., Hou, H. (2014), Design and implementation of a new autonomous sensor fish to support advanced hydropower development. Review of Scientific Instruments 85, 115001.

Engel, M. (2012), The chronology of prehistoric high-energy wave events (tropical cyclones, tsunamis) in the southern Caribbean and their impact on coastal geo-ecosystems - a case study from Bonaire (Leeward Antilles). Dissertation an der Mathematisch-Naturwissenschaftlichen Fakultät, Universität zu Köln, URL: http://kups.ub.uni-koeln.de/4710/ (last access 8th June 2015).

Engel, M., Brückner, H., (2011). The identification of palaeo-tsunami deposits - a major challenge in coastal sedimentary research. Coastline Reports 17, 65-80.

Engel, M., Brückner, H., Messenzehl, K., Frenzel, P., May, S.M., Scheffers, A., Scheffers, S., Wennrich, V., Kelletat, D. (2012), Shoreline changes and high-energy wave impacts at the leeward coast of Bonaire (Netherlands Antilles). Earth, Planets and Space 64: 905-921.

Engel, M., Brill, D., May, S.M., Reyes, M., Brückner, H. (2014), Philippinen: "Haiyans" Erbe. Geographische Rundschau 66 (6), 54-57.

Etienne, S., Buckley, M., Paris, R., Nandasena, A.K., Clark, K., Strotz, L., Cagué-Goff, C., Goff, J., Richmond, B. (2011), The use of boulders for characterizing past tsunamis: lessons from the 2004 Indian Ocean and 2009 South Pacific tsunamis. Earth-Science Reviews 107, 76-90.

GEBCO (2014), The GEBCO One Minute Grid. http://www.gebco.net/data_and_products/gridded_bathymetry_data/.

Gornak, T. (2013), A goal oriented survey on immersed boundary methods. Berichte des Fraunhofer Techno- und Wirtschaftsmathematik, 235, ISSN 1434-9973.

Goto, K., Okada, K., Imamura, F. (2010), Numerical analysis of boulder transport by the 2004 Indian Ocean tsunami at Pakarang Cape, Thailand. Marine Geology 268, 97-105.

Hisamatsu, A., Goto, K., Imamura, F. (2014), Local plaeao-tsunami size evaluation using numerical modelling for boulder transport at Ishigaki Island, Japan. Episodes 37(4), 265-276.

Huntington, K., Bourgeois, J., Gelfenbaum, G., Lynett, P., Jaffe, B., Yeh, H., Weiss, R. (2007), Sandy signs of a tsunami's onshore depth and speed. Eos 88, 577-578.

Imamura, F., Goto, K., Ohkubo, S. (2008), A numerical model of the transport of a boulder by tsunami. Journal of Geophysical Research - Oceans 113, C01008.

Intergovernmental Oceanographic Commission (2012), Exercise Caribe Wave/Lantex 13. A Caribbean Tsunami Warning Exercise, 20 March 2013. Volume 1: Participant Handbook. IOC Technical Series No. 101. Paris, UNESCO.

Iglberger, K., Rüde, U. (2009), Massively Parallel Rigid Body Dynamics Simulations. Computer Science - Research and Development 23 (3), 159-167.

Jarvis, A., Reuter, H.I., Nelson, A., Guevara, E. (2008), Hole-filled SRTM for the globe Version 4, available from the CGIAR-CSI SRTM 90m Database. http://srtm.csi.cgiar.org.

Knutson, R.T., McBride, J.L., Chan, J., Emanuel, K., Holland, G., Landsea, C., Held, I., KossinN, J.P., Srivastava, A.K., Sugi, M. (2010), Tropical cyclones and climate change. Nature Geoscience 3, $157-163$. 
Lander, J.F., Whiteside, L.S., Lockridge, P.A. (2002), A brief history of tsunamis in the Caribbean Sea. Science of Tsunami Hazards 20, 57-94.

Liu, H., Sakashita, T., Sato, S. (2014), An experimental study on the tsunami boulder movement. Coastal Engineering Proceedings 34, currents. 16.

Martinez, C., Garcia-Martinez, R., Miralles-Wilhelm, F. (2011), A two-phase debris flow model with boulder transport. International Journal of Safety and Security Engineering, 1(4), 389-402.

Nandasena, N.A.K., Paris, R., Tanaka, N. (2011a), Reassessment of hydrodynamic equations: Minimum flow velocity to initiate boulder transport by high energy events (storms, tsunamis). Marine Geology 281, 70-84.

Nandasena, N.A.K., Paris, R., Tanaka, N. (2011b), Numerical Assessment of boulder transport by the 2004 Indian Ocean tsunami in Lhok Nga, West Banda Aceh (Sumatra, Indonesia). Computers \& Geosciences 37, 1391-1399.

Nandasena, N.A.K., Tanaka, N. (2013), Boulder transport by high energy: Numerical model-fitting experimental observations. Ocean Engineering 57, 163-179.

Neumann, B., Vafeidis, A.T., Zimmermann, J., Nicholls, R.J. (2015), Future coastal population growth and exposure to sea-level rise and coastal flodding - a global assessment. PLOS ONE 10 (3), e0118571.

NOAA (2014). Natural Hazard Viewer. http://maps.ngdc.noaa.gov/viewers/hazards/.

Noormets, R., Crook, K.A.W., Felton, E.A, (2004), Sedimentology of rocky shorelines: 3. Hydrodynamics of megaclast emplacement and transport on a shore platform, Oahu, Hawaii. Sedimentary Geology 172, 41-65.

Oetjen, J., Engel, M., Effkemann, C., May, S.M., Pudasaini, S.P., Wöffler, T., Aizinger, V., Schüttrumpf, H., Brückner, H. (2015), Numerical modelling of tsunami scenarios for the island of Bonaire (Leeward Antilles). In: The 4th International Tsunami Field Symposium, 2015.

Peltzer, S. (2015), Planung, Entwurf, Konstruktion und Realisierung eines physikalischen Modellversuchs zur Generierung einer schiffserzeugten Primärwellenbelastung auf Strombauwerke an Wasserstraßen. Master Thesis, Faculty of Civil Engineering, RWTH Aachen University (unpublished).

Penchev, V. (2008), Extreme solitary waves at restricted water depth. Coastlab08, Book of Abstracts, Nuova Editoriale, Italy.

Pignatelli, C., Sansó, P., Mastronuzzi, G. (2009), Evaluation of tsunami flooding using geomorphologic evidence. Marine Geology 260, 6-18.

Prizomwala, S.P., Gandhim, D., Ukey, V.M., Bhatt, N., Rastogi, B.K. (2015), Coastal boulders as evidences of high-energy marine events from Diu Island, west coast of India: storm or palaeotsunami? Natural Hazards 75 (2), 1187-1203.

Pudasaini, S.P. (2012), A general two-phase debris flow model. Journal of Geophysical Research: Earth Surface 117: F03010.

Scheffers, A. (2005), Coastal response to extreme wave events - hurricanes and tsunamis on Bonaire. Essener Geographische Arbeiten 37.

Spiske, M., Böröcz, Z., Bahlburg, H. (2008), The role of porosity in discriminating between tsunami and hurricane emplacement of boulders - A case study from the Lesser Antilles, southern Caribbean. Earth and Planetary Science Letters 268: 384-396.

Sugawara, D., Minoura, K., Imamura, F. (2008), Tsunamis and tsunami sedimentology. In: Shiki, T., Tsuji, Y., Yamazaki, T., Minoura, K. (eds.), Tsunamiites - Features and Implications. Elsevier, Amsterdam, Oxford, pp. 9-49.

Sugawara, D., Goto, K., Jaffe, B.E. (2014), Numerical models of tsunami sediment transport - Current understanding and future directions. Marine Geology 352, 295-320.

Terry, J., Lau, A.Y.A., Etienne, S. (2013), Reef-Platform Coral Boulders - Evidence for High-Energy Marine Inundation Events on Tropical Coastlines. Springer, New York.

Vose, S.R., Applequist, S., Bourassa, M.A., Pryor, S.C., Barthelmie, R.J., Blanton, B., Bromirski, P.D., Brooks, H.E., De Gaetano, A.T., Dole, R.M., Easterling, D.R., Jensen, R.E., Karl, T.R., Katz, R.W., Klink, K., Kruk, M.C., Kunkel, K.E., Mac Cracken, M.C., Peterson, K.S., Thomas, B.R., Walsh, J.E., Wang, X.L., Wehner, M.F., Wuebbles, D.J., Young, R.S. (2014), Monitoring and understanding changes in extremes - extratropical storms, winds, and waves. Bulletin of the American Meteorological Society 95(3), 377-386. 
Watt, S.G., Jaffe, B.E., Morton, R.A., Richmond, B.M., Gelfenbaum, G. (2010), Description of extreme-wave deposits on the northern coast of Bonaire, Netherlands Antilles. USGS Open-File Report 2010-1180.

Zainali, A., Weiss, R. (2015), Boulder dislodgement and transport by solitary waves: Insights from three-dimensional numerical simulations. Geophysical Research Letters 42, doi: 10.1002/2015GL063712. 